\title{
Educação e Ludicidade: um diálogo acerca das possibilidades epistêmicas que a abordagem lúdica têm a oferecer a Sociologia
}

\section{Education and Playfulness: a dialogue about the epistemic possibilities that playful approach have to offer Sociology}

\author{
Mauro Meirelles \\ Doutor em Antropologia Social \\ Unisinos \\ mauro@cirkula.com.br \\ Luciana Hoppe \\ Mestre em Administração \\ Uniritter \\ lhoppe@brturbo.com.br \\ Simone L. Sperhacke \\ Doutoranda em Design e Tecnologia \\ simone@sisperdesign.com
}

\begin{abstract}
Resumo: A partir de entrevistas realizadas com as professoras Luciana Hoppe e Simone L. Sperhacke buscou-se trazer algumas contribuições que a educação lúdica tem a oferecer ao campo das Ciências Sociais. Num tom de diálogo, busca trazer algumas definições, apontar ideias e pensar a relação professor-aluno pelo uso de jogos em sala de aula. Luciana é comunicadora, especialista e mestre em marketing, professora universitária desde 1999, tem formação em Metodologia Cefe e Focalização de Jogos. Além da docência presencial e em EAD, atua na gestão no Ensino Superior, tem atuando com pesquisa e consultoria desde 1990 e é proprietária da SIM!. Simone é Desenhista Industrial, mestre e doutoranda em design e tecnologia, Participa como pesquisadora no Projeto ICD do Núcleo de Desenvolvimento de Produtos (NDP) da UFRGS desde 2009, professora universitária, tem formação em focalização de Jogos e facilitação gráfica, especialização em design de jogos e é proprietária da Sisper Design.
\end{abstract}

Palavras-chave: Educação, Ludicidade, Jogos.

Abstract: From interviews with teachers Luciana Hoppe and Simone L. Sperhacke, we intend to bring some contributions that playful education has to offer to the field of Social Sciences. In a dialogue spirit, intends to bring some definitions, point ideas and thinking about teacher-student relationship by using games in the classroom. Luciana is a communicator, expert and master in marketing, university professor since 1999, has a background in Cefe Methodology and Games. In addition to classroom teaching and distance learning, she is engaged in college management, works with research and consulting since 1990 and owns the SIM!. Simone is Industrial Designer, master and doctoral student in design and technology, participates as a researcher in the ICD Project from Product Development Center (NDP) of UFRGS since 2009, a university professor, has background in focus games and graphic facilitation, expertise in design games and owns the Sisper Design.

Key-words: Education, Playfulness, Games

Originais recebidos em: 10/03/2016

Aceito para publicação em: 20/06/2016

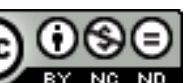

Comercial-Vedada a criação de obras derivadas 3.0 Unported License.

Revista Em Debate (UFSC), Florianópolis, volume 13, p. 162-180, 2015. ISSNe 1980-3532 
Mais do que um texto meramente acadêmico, nas páginas seguintes, a partir de algumas entrevistas realizadas com as professoras Luciana Hoppe e Simone L. Sperhacke buscou-se trazer algumas contribuições que a educação lúdica tem a oferecer ao campo das Ciências Sociais. Neste sentido, seu tom é muito mais de diálogo e busca, de certa forma, pensar o campo, trazer algumas definições, apontar ideias e pensar a relação professor-aluno a partir do uso de jogos em sala de aula.

De certa forma, posso dizer que esse diálogo não parte do nada, pois já sabia o que queria explorar nesta entrevista fazia quase um ano quando a primeira das entrevistadas realizou uma oficina com os alunos do Curso de Especialização em Ensino de Sociologia para o Ensino Médio da UFRGS, em 2015. E, se, a oportunidade faz o ladrão, esse é o momento então de compartilharmos os achados e levar a outros colegas um pouco da riqueza do trabalho das duas professoras.

Outrossim, no decorrer do texto optamos por deixar os marcadores de quem está a falar e a perguntar, com vistas a dar um tom mais informal e de diálogo ao texto. Então, vamos a esse bate e rebate de questionamentos e respostas. E... Luzes, Câmera, Ação!

Mauro: Primeiramente, prezadas Luciana e Simone, gostaria de agradecer a disponibilidade de vocês. E, gostaria de iniciar esse diálogo pedindo que vocês exponham aos nossos leitores de que forma a educação lúdica é definida e como se percebe ou concebe o processo de aprendizagem na perspectiva da educação lúdica?

Luciana: Eu acho que a primeira coisa que a gente tem que falar é que o lúdico está quase sempre ligado a ideia de diversão e prazer, e isso, muda tudo na concepção da educação. Porque quando as pessoas aprendem com prazer e diversão elas colocam menos barreiras no seu aprendizado e são mais produtivas naqueles aprendizados que estão incorporando.

Simone: Com certeza. Eu concordo contigo e acrescento que tudo que é feito com prazer tem um resultado que fica muito mais enraizado na memória do ser humano. Quando há qualquer sentimento envolvido, seja ele positivo ou negativo, há sempre maior fixação da experiência e dos conteúdos ligados a tal experiência. 
Luciana: Exato. E isso tem a ver com a neuroaprendizagem. Pois, como muitos estudos mostram tem-se que a conexão neural é mais forte quando se está trabalhando com a via da emoção. E, em função disso, tem-se que tais conexões acontecem de forma bem mais rápida de modo que, o aluno acaba aprendendo sem se dar conta. Nesse sentido, é muito comum que nos feedbacks, nossos alunos, digam: eu aprendi e nem me dei conta que eu estava estudando.

Simone: Exatamente. Quando eles aprendem com jogos essa reação é muito mais forte e incrível. Além disso, quando começamos a trabalhar com a abordagem lúdica, em geral, as pessoas se mostram bastante incrédulas. Mas depois que elas vivenciam o modo como trabalhamos com o lúdico, a resposta é exatamente essa que a Luciana destacou de modo que, a partir das vivências que têm conosco, elas, começam a acreditar que é possível potencializar a aprendizagem através do uso de jogos em sala de aula.

Luciana: É incrível. Também é importante mencionarmos que muitos conhecem a Educação Lúdica no contexto da educação infantil e esquecem que, esta, também, pode ser usada em outros contextos. Motivo pelo qual, os adultos, na maioria das vezes, se mostram bastante reticentes. Mas quando nós aplicamos esta metodologia no contexto dos adultos, ela traz resultados muito surpreendentes e positivos.

Simone: E muitas vezes além de surpreendentes, superiores aos alcançados com o uso de outras metodologias.

Luciana: Exato, por que o que acontece na educação de adultos hoje? Temos uma geração de adultos que teve uma educação muito formal, muito dentro do copiar do quadro e repetir, decorar. E aí quando você vem uma proposta de Educação Lúdica, que faz pensar, você quebra um pouco esse ciclo. E aí as pessoas redescobrem o prazer de aprender, que é o que se tinha quando criança. Éramos curiosos por natureza, mas, aos poucos, com essa padronização de educação, essa curiosidade do aprender foi se perdendo.

Simone: E, o aluno acaba fazendo tudo de forma apenas mecânica, ele não é mais instintivo. E o instintivo nos deixa sempre muito mais hábil e curioso. A curiosidade faz Revista Em Debate (UFSC), Florianópolis, volume 13, p. 162-180, 2015. ISSNe 1980-3532 
com que o cérebro desenvolva mais, aumentando a plasticidade. E assim, é possível enxergar que com os jogos e com as brincadeiras (porque a gente não está falando só dos jogos, mas também das brincadeiras e dinâmicas) a questão lúdica ganha outros contornos. E, a vivência do lúdico traz um diferencial enorme e faz com que a chance de lembrar-se daquilo que é vivenciado seja muito maior. Sendo assim, o que se busca a partir dessa concepção é romper com esse processo de copiar, repetir e decorar trazendo novos contornos e modos de se ensinar e aprender.

Mauro: Mas isso se aplica a qualquer contexto de ensino-aprendizagem sejam eles formais e informais? Como a educação lúdica se insere nesse processo?

Simone: A gente já comentou sobre isso, mas vale repetir que a aprendizagem (como vários alunos comentam) quando na forma lúdica, com jogos, acontece de forma espontânea e informal. E essa aprendizagem acontece de uma forma agradável e tão subjetiva que o processo torna-se quase imperceptível. Por isso, muitas vezes, o jogo utilizado na sala de aula sofre um preconceito (principalmente quando se trata de adultos), porque ele tem o sentido de diversão e as pessoas se perguntam: como posso aprender se eu estou me divertindo? Afinal aprender é um processo doloroso - algo que para nós já é passado - mas que, para muitos ainda é tido como uma realidade. Sendo assim, tem-se que é possível aprender se divertindo e sem se dar conta disso durante o processo, como mostram muitas pesquisas realizadas.

Luciana: Ainda nesta direção é importante lembrar que o processo de ensino e aprendizagem a partir da perspectiva da ludicidade não é tido como um processo unilateral. Assim, o professor que for se aventurar na educação lúdica, tem que ter consciência disso e estar preparado para tal fim. Pois, senão ele corre o risco de justamente fazer aquilo que a gente estava falando antes: de fazer o jogo pelo jogo. Ou seja, se o jogo não estiver dentro de um contexto ele perde seu sentido para a educação. É preciso amarrar os jogos com os conteúdos trabalhados e usar outras metodologias de ensino e aprendizagem ao mesmo tempo. Em função disso, nunca é demais lembrar que, porque nós estamos trabalhando com a educação lúdica, isso, não significa que o aluno não vai ler, não vai pesquisar e que, o professor, não vai dar uma aula expositiva também. Mas, que isso pode ser feito de outra maneira, de forma mais dinâmica, mais produtiva. Assim, ao executar uma tarefa - como jogar, por exemplo - é preciso que Revista Em Debate (UFSC), Florianópolis, volume 13, p. 162-180, 2015. ISSNe 1980-3532 
elaboremos algumas estratégias e hipóteses. E, dependendo do resultado do jogo, vamos confirmar ou desconfirmar estas hipóteses, refazendo ou não, assim, nossas estratégias.

Mauro: E, agora, indo mais fundo na questão da ludicidade. Vocês poderiam explorar um pouco alguns conceitos importantes dos jogos e algumas teorias que sustentam o uso dos jogos na educação?

Simone: Podemos começar lembrando uma frase clássica de Confúcio: Diga-me, esqueço. Mostre-me, eu lembro. Envolva-me, eu aprendo. E nada envolve mais do que experiência, do que o experimentar e vivenciar situações. Nesse sentido os jogos são excelentes ferramentas para essa vivência. Eles nos remetem a uma vivência simulada, mas é uma vivência que faz uma ponte importante entre a teoria e a vida real, alinhando a teoria com a prática.

Luciana: Mas, precisamos lembrar do conceito de jogo que o Huizinga (Homo Ludens: o jogo como elemento da cultura) nos traz, pois, ele já estudava a presença dos jogos na cultura há muito tempo. Huizinga é um dos autores mais citados e significativos na área de jogos. E sua obra não é nada moderna. Seu livro é de 1938, mas ele conseguiu fazer uma análise do papel do jogar dentro da nossa cultura e é quase uma antropologia do jogar.

Simone: Na verdade ele elabora um pensamento filosófico sobre o jogo. Fala da questão de que o jogo é anterior à própria humanidade. E, relata que os animais entre si brincam e jogam, simulando situações de caça ou de conflito, por exemplo. Ou seja, os animais, jogavam antes mesmo de serem domesticados, treinando habilidades que no futuro usarão para sobrevier. E, neste sentido, Huizinga ilustra muito bem isso quando escreve que "o jogo inicia-se e, em determinado momento acabou. Joga-se até que se chega a um certo fim. Enquanto está ocorrendo tudo é movimento, mudança, alternância, sucessão, associação e separação...”. (2008, p.12).

Luciana: E no momento em que vamos passando por essas experiências todas, a gente vai fixando o aprendizado resultante delas na nossa memória. E nesse sentido, acho importante falar sobre o que caracteriza um jogo. 


\section{Mauro: Então, o que é jogar? O que é um jogo?}

Simone: Com vistas a responder a essas duas questões, podemos fazer uso de uma citação que é normalmente atribuída a John Von Neumann, a qual, parte do suposto de que "o jogo é toda e qualquer interação entre dois ou mais sujeitos dentro de um conjunto pré-definido de regras". É uma definição simples, mas muito completa. E aí é a gente pode salientar a necessidade de interação entre dois ou mais sujeitos. Mas, esses sujeitos não precisam ser necessariamente dois seres humanos...

Luciana: Claro, um sujeito sou eu e o outro pode ser uma parede, por exemplo, quando eu jogo bola contra uma parede e rebato. Assim eu estou interagindo com a bola e com a parede. Quando eu jogo o resta $\mathrm{um}^{1}$ eu estou interagindo com o tabuleiro, quando eu jogo paciência estou interagindo com as cartas. E bem importante também são as regras...

Mauro: Vocês poderiam me falar um pouco mais disso e porque as regras são tão importantes?

Simone: Porque se não tem regras é somente brincar, e brincar e jogar tem essa diferença: o jogo tem regras pré-definidas. É claro que, muitas vezes a brincadeira da criança também tem regras, mas regras que a criança acaba criando durante o brincar. $\mathrm{E}$ quando isso acontece e a criança cria regras, a brincadeira deixa de ser brincadeira e se torna um jogo de regras estruturadas.

Luciana: Um pouco disso a gente observa nas crianças. Elas dizem: mas o dono da brincadeira sou eu, porque fui eu que inventei a regra! Então, é ela quem diz o que pode e o que não pode e estabelece limites. Neste sentido, é interessante observar que às vezes fazemos jogos com alunos e deixamos esses sem muitas regras estabelecidas a priori e as pessoas, mesmo sem querer ou ter consciência, acabam criando ou supondo a existência de regras que a gente nem falou ou previu.

Simone: Exatamente, elas inventam as regras e às vezes tornam o jogo mais complexo e mais difícil do que a ideia original.

\footnotetext{
${ }^{1}$ Jogo de tabuleiro também chamado de solitário, com apenas um jogador por vez no qual o objetivo é, por meio de movimentos válidos, deixar apenas uma peça no tabuleiro.

Revista Em Debate (UFSC), Florianópolis, volume 13, p. 162-180, 2015. ISSNe 1980-3532
} 
Luciana: Como quando aplicamos aquele jogo da Ilha que os participantes devem salvar a população. A gente só diz o que não pode fazer e não diz o que fazer, e os jogadores acabam determinando regras por conta própria. Eles determinam que não podem uma coisa e no final das contas acabam descobrindo que poderiam e que foram eles que colocaram essa barreira.

Simone: E essa barreira pode acontecer na educação também. O aluno cria uma barreira acreditando que não vai conseguir, ou que não é capaz e coloca essa barreira antes mesmo de aprender. E, neste sentido, vale citar também uma frase que eu gosto muito: "Embora a aprendizagem seja um negócio sério, pressão e emoções negativas podem ficar no caminho de uma pedagogia de sucesso. O humor é uma boa forma de desviar a atenção desses problemas", ou seja, embora a educação seja um negócio sério isso não quer dizer que as atividades educacionais não possam ser divertidas (Strean, 2011).

Luciana: Essa é a grande quebra de paradigma que eu considero que a Educação Lúdica faz. Pois você pode aprender de uma maneira divertida e leve. E aí, ir à escola não é "castigo", fazer prova não é "castigo", tarefa não é algo chato, que você está livre e que quem está ganhando no momento em que se aprende é você mesmo.

Simone: Albert Einstein já dizia que jogar é a forma mais elevada de pesquisar...

Mauro: E na opinião de vocês, quando é que um professor tem que usar uma aula ludificada?

Luciana: A gente usa sempre! Mas, o professor que não está acostumado com isso tipo de trabalho deve estar atento ao fato de que, ele, deve se sentir seguro para usar uma aula "ludificada". E, se ele se sente seguro, ele deve usar. E não precisa ser a aula toda "ludificada", pode ser um momento da aula, da disciplina ou de uma temática. Mas tem situações em que o uso da Educação Lúdica é muito indicado e pertinente como quando, você tem alunos indisciplinados ou um estímulo mais interessante e mais dinâmico que a sua aula, por exemplo. 
Simone: As regras do jogo trazem a disciplina para o grupo e como se está dentro daquele círculo mágico, que o aluno só entra se quiser, quando jogando, está praticando a disciplina.

Luciana: Claro. E o interessante é que às vezes você tem um aluno que não está nem aí... que ele é até escanteado pela turma. E aí quando joga, se destaca. Nesse sentido, o uso de jogos é apropriado quando se tem situações de bullying na sala de aula, pois você consegue, com o jogo, às vezes descobrir potencialidades em alunos que eles não aparentavam ter e começamos a ver o despertar daquele aluno e, daí a relação dele com os colegas muda.

Simone: Mas, também existem outras situações que se pode chamar a atenção, que também são apropriadas para o uso de aulas lúdicas quando, por exemplo, existe a falta de concentração dos alunos, a falta de motivação dos alunos, a falta de interesse pelo assunto ou, ainda, quando se percebe que existe pouco rendimento em relação aos conteúdos. Nesse caso, quando trabalhamos com jogos estamos buscando aumentar a disciplina, motivar e aumentar o foco e a concentração dos alunos.

Luciana: E tudo isso tem relação com a forma com que aprendemos. Como cita Miller, por exemplo.

Simone: Isso, a pirâmide do conhecimento de Miller (Schell, 2014) mostra que na base da pirâmide está o que se "sabe". Ou seja, para qualquer conhecimento, precisamos primeiro dos conceitos básicos. Depois, seguindo a pirâmide, temos "sabe como", que é um avanço em relação aos conceitos básicos e uma noção de sua utilidade. Depois, seguindo nesta pirâmide temos "mostra como", que deixa implícita a ideia de que se sabe demonstrar o conhecimento. Por fim, no topo da pirâmide, o pináculo do conhecimento, que é o "fazer", ou quando, se domina um conhecimento e sabe-se aplicá-lo na prática. E, é essa prática que o jogar proporciona, de maneira simulada.

Luciana: Claro! Porque você só vai saber fazer alguma coisa se você realmente aprendeu. Se não você não sabe fazer é porque ainda não aprendeu. Então, vê como isso é muito parecido com o que Delors (2012) aponta, sobre os 4 pilares do conhecimento. Pois, não adianta uma pessoa ter conhecimento de um conteúdo de maneira teórica Revista Em Debate (UFSC), Florianópolis, volume 13, p. 162-180, 2015. ISSNe 1980-3532 
apenas. Ela precisa saber colocar esse conteúdo no contexto. E assim, quando se usa o conteúdo de outro contexto e se sabe aplicar ele em um novo cenário é sinal que houve aprendizado. Então é justamente o que a gente faz no jogo, a gente usa um contexto divertido e lúdico dentro daquele círculo mágico que o Huizinga fala para treinar a aplicação de conceitos. Mas quando chegar no contexto da vida real e essa pessoa aprendeu, ela saberá como colocar isso em prática. Ou seja: as pessoas treinam em um contexto mais flexível, onde se pode errar e simular. E depois, aplicam isso na vida real com mais segurança. Essa é a base, portanto, sobre a qual opera a abordagem lúdica.

Simone: Outro ponto importante é a questão do foco do aluno. Precisamos sempre cuidar com muita atenção os desafios e as habilidades do grupo. Se criamos um ambiente com muitos desafios e poucas habilidades, a gente vai ter um ambiente de ansiedade. Agora se trabalhamos com alunos que tenham muitas habilidades e propomos poucos desafios, entramos em uma zona de tédio. Por exemplo, em Educação Física: Se eu só consigo saltar uma altura de 20 centímetros e me colocarem um desafio de 80 centímetros, eu vou entrar em uma zona de ansiedade. Ao mesmo tempo em que se eu salto 80 centímetros de altura e me colocam um desafio de apenas 20 centímetros eu vou entrar em uma zona de tédio. Por isso, é importante criar um canal de fluxo, porque os alunos têm habilidades e conhecimentos diferentes e para isso o professor deve conhecer um pouco o seu grupo (jogos também são ótimos para isso!).

Luciana: Para fechar um pouco essa questão é importante mencionarmos que acreditamos que o jogo pode transformar a educação e a nossa vivência de sala de aula. Podemos mudar a ideia antiga que a educação é feita com dor. Mas que acreditamos que o jogo pode transformar a educação em uma atividade tão prazerosa, e, conforme alguns alunos que já participaram de nossas aulas disseram, a gente aprende e nem percebe, ao mesmo tempo em que se diverte. E os exemplos disso não são poucos. Em alguns países, como a Finlândia, por exemplo, já se está adotando um novo conceito de sala de aula, com uma abordagem multidisciplinar e interdisciplinar onde os alunos aprendem fazendo, executando projetos, sem aquela aula compartimentada, dividida por matérias. Mas, isso tudo tem a ver com uma mudança que é necessária na educação. Porque quando vamos resolver problemas na vida real nós somos multitarefa. Ou seja, não vamos usar só a matemática, só o emocional, usamos um conjunto de habilidades. E a Educação Lúdica é ótima para trabalhar habilidades em conjunto. Pois, para você jogar Revista Em Debate (UFSC), Florianópolis, volume 13, p. 162-180, 2015. ISSNe 1980-3532 
um jogo você precisa saber português, por que tem que ler e interpretar a regra para saber aplicá-la. É preciso saber lógica, porque muitas vezes sua estratégia vai depender da forma como você interpreta e opera com as regras de modo que, seu desempenho no jogo depende disso. Um jogo envolve, em geral, uma pluralidade de saberes e habilidades de modo que, a partir de uma única experiência você está trabalhando múltiplas habilidades. E, isso você só consegue a partir da Educação Lúdica.

Mauro: E, falando ainda sobre a Educação Lúdica, vocês poderiam explorar um pouco mais o modo como à relação aluno-professor é pensada a partir da perspectiva da Educação Lúdica?

Luciana: Primeiramente, devemos ter claro que a relação entre o aluno e o professor fica muito mais próxima quando trabalhamos com o enfoque da Educação Lúdica. Até porque para se jogar com outra pessoa, em um primeiro momento é necessário estabelecer-se para com esta uma relação de confiança. E, com a Educação Lúdica quebramos alguns paradigmas de sala de aula como, por exemplo, aqueles que colocam o professor de um lado e o aluno de outro, aquele que parte do pressuposto que o professor está ali somente para dar uma nota e avaliar o aluno, ou ainda, que o aluno está ali para ganhar uma nota e passar. Então, eu acho que quando trabalhamos com a ludicidade, quebramos um pouco deste paradigma.

Simone: Sim, e colocamos todos em um mesmo patamar.

Luciana: Exato, todos no mesmo patamar, todos jogando juntos, pois a Educação Lúdica trabalha pela a linha da emoção.

Simone: Sim, e também quebramos a questão da hierarquia, aproximando as pessoas. Como no exemplo que gostamos de dar: em um jogo de futebol do time de uma empresa, você não vai querer no teu time o CEO se ele é um "pé quebrado", que não joga nada (...). Talvez você escolha o cara da faxina, que joga bem para caramba. E, então, se perde, no momento do jogo, esta questão da hierarquia e as pessoas ficam mais próximas. E quando isso acontece em sala de aula, o professor vai sair daquele patamar que tem na frente da sala de aula, pois por muito tempo foi considerado o "todo poderoso" na educação e vai sentar junto com o aluno, no mesmo patamar e vai jogar Revista Em Debate (UFSC), Florianópolis, volume 13, p. 162-180, 2015. ISSNe 1980-3532 
junto. Talvez, este professor cometa erros, ganhe, perca (...). Talvez o aluno tenha uma estratégia melhor. Enfim, é tudo uma questão de jogar o jogo.

Luciana: E aí se estabelece uma relação bastante diferente (...). E nesse sentido, considero importante que abordemos a questão de poder errar (...). Essa questão exige do professor outra postura. Nós sempre costumamos falar e partir do princípio de que se as pessoas estão chegando naquela sala de aula é porque elas têm algo a aprender, elas não vieram prontas. E aí se estabelece um processo de construção, dos saberes, dos conhecimentos, das habilidades e das competências que este indivíduo precisa desenvolver ali. Então, esperar que ele não vá cometer nenhum erro é uma ilusão, uma utopia. Isto não vai acontecer. E ainda, como já falamos antes, se a gente parte do princípio de que o jogo desenvolve nas pessoas uma competência muito importante, que é a resiliência, a gente tem que admitir o erro como uma parte do processo.

Simone: Isso, uma parte importante, fundamental do processo. É importante errar para aprender.

Luciana: Isso, e ainda, trabalhar dentro de um contexto. Porque a educação lúdica não está fora do contexto de outros estudos sobre a educação. Paulo Freire, por exemplo, quando fala da importância da problematização e aborda a necessidade de conhecer a realidade dos indivíduos que estão no processo de ensino aprendizagem e coloca ainda a importância de construir novos conhecimentos a partir de conhecimentos prévios destas pessoas, ele está falando de dar significado à aprendizagem. Ele, talvez, não com este nome, está se referindo ao que chamamos na neuroapredizagem do processo de ancoragem. Então, Paulo Freire está justamente falando sobre a necessidade de sair deste contexto clássico de sala de aula e buscar outro contexto mais referenciado, mais significativo. Assim, quando trabalhamos com jogos em sala de aula nós estamos buscando justamente um significado dentro de outra realidade que não é como Paulo Freire fala, uma realidade concreta, mas sim uma realidade lúdica. Porque é importante que a gente considere o que acontece conosco quando jogamos, nos abrimos mais e criamos (...).

Simone: Sim, e nos colocamos no interior do "círculo mágico" que o Huizinga menciona, que é, segundo ele, um ambiente no qual trazemos nosso eu verdadeiro à Revista Em Debate (UFSC), Florianópolis, volume 13, p. 162-180, 2015. ISSNe 1980-3532 
tona. E esse círculo mágico não acontece somente durante o jogar, naqueles 30 ou 40 minutos que estamos diretamente envolvidos na dinâmica do jogo (...). Ele se perpetua (...). Ele continua (...). Essa relação, este vínculo com os jogadores, ele permanece, mesmo depois de terminado o jogo. Por isso que Huizinga chama este momento de círculo mágico, pois ali tudo pode acontecer. Ali, você pode ser quem você quiser, você pode ter uma persona diferente a cada jogada (...). Você pode errar, pode acertar (...). Pode ganhar ou perder (...). E o mais importante, depois, podemos começar tudo de novo, com outras estratégias.

Luciana: Exato, mas para que isto se estabeleça é importante que o jogo tenha regras estabelecidas. E, já que estamos falando da relação entre aluno e professor, nesse sentido, o próprio aluno pode ser responsável por essas regras. Assim, podemos fazer um exercício interessante, que é empoderar o aluno e desempoderar o professor. E no momento em que o aluno for criar um jogo dentro da sala de aula, o que é muito comum, ele pode ele mesmo desenvolver as suas regras, a partir dos conteúdos trabalhados em aula.

Simone: E como este aluno vai jogar o jogo também, espera-se que ele seja bem coerente ao desenvolver as regras. Ou seja, que ele não coloque só coisas fáceis, ou só coisas difíceis, porque ele mesmo vai estar envolvido no jogar.

Luciana: É uma questão mais justa, é disto que estamos falando. E temos sempre um desafio na educação lúdica, que é aquele indivíduo que não quer jogar. Nós, como professoras, planejamos um jogo, chegamos à sala de aula e tem aquele aluno que diz: Eu não vou jogar! Eu não gosto de jogos! E aí nós temos que ter uma postura de professor e respeitar esta vontade do outro indivíduo de não querer jogar. Porque o jogo só vai ter sentido de diversão e prazer, e por consequência proporcionar o aprendizado, se a pessoa for se envolver nas atividades de boa vontade, voluntariamente. Se ela for obrigada, vai perder todo o sentido. Então, o que a nossa experiência mostra é que quando existem estes indivíduos que não querem jogar, a gente encontra algo para esta pessoa fazer como, por exemplo, marcar o tempo, cuidar as regras, observar, moderar, marcar os pontos, etc.

Simone: Isso mesmo, encontramos para este aluno um outro papel na situação. 
Luciana: Exato. E na medida em que este aluno que não quer jogar vai vendo os outros jogarem e se divertir, ele, vai aos poucos, cedendo e entrando no jogo. Em $99 \%$ das situações é exatamente isso que acontece. Na nossa experiência é isso que acontece. Então aí, se mostra um papel de professor muito diferente. Um professor muito mais companheiro, participativo, cúmplice (...). E aí se perde aquela ideia antiga de que o aluno é um ser vazio, não iluminado (alumni, no latim) e que o mestre é aquele que sabe tudo. Por isso, como já reiteramos várias vezes, é preciso que o professor que trabalhe com educação lúdica tenha um perfil especial, que seja muito competente nos conteúdos, que lide muito bem com as emoções e que saiba se relacionar com diferentes pessoas e públicos.

Simone: Isso. Pois, senão, esse professor não terá jogo de cintura nas situações não planejadas que podem se apresentar. O jogo mexe com o emocional das pessoas e, muitas vezes, podem ocorrer reações que o professor não estava esperando. Porque no jogo não existe só alegria. Existe também raiva, frustração, medo e insegurança, sentimentos esses que podem ser despertados no e pelo jogo. Então, as pessoas podem, algumas vezes, se desestruturar durante o jogo e o professor tem que ter a devida flexibilidade para auxiliar na condução desta situação.

Mauro: E, pensando na realidade da sala de aula, vocês podem citar alguns exemplos de jogos e dinâmicas que vocês têm aplicado em suas aulas/cursos e como estão sendo os resultados disso?

Simone: Um jogo bem simples que nós já aplicamos é o Jogo do Ganso, que é um jogo de percurso e que há situações em cada casa e nelas acontece uma evolução ou uma involução. Como sorte ou revés (...). Esse é um jogo que nós já usamos em sala de aula e no que diz respeito à sorte o jogador tinha que responder uma questão do assunto, da temática. Então é uma forma muito fácil de adaptar qualquer assunto que esteja sendo discutido em sala de aula ou que esteja sendo desenvolvido aprendizado.

Luciana: Porque o Jogo do Ganso é um jogo de trilha. É o jogo mais clássico que existe. Nele tem que andar casinhas para frente e casinhas para trás. E ganhar pontos e perder pontos ou ganhar moedas (...).

Revista Em Debate (UFSC), Florianópolis, volume 13, p. 162-180, 2015. ISSNe 1980-3532 
Simone: Quando aplicamos, nós nem tínhamos moedas, usamos clipes de papel para contar e marcar os pontos. E essa foi uma experiência bem interessante e é simples de adaptar a qualquer assunto.

Luciana: Outros jogos que lembro são os de quebrar gelo. Como o Fornicuti, por exemplo, que é aquele jogo que vão mudando os comandos. O primeiro comando é o pá, com o bater de palma. Depois é o flash que muda a direção do pá. Depois usamos o shiva, que direciona o jogo para uma pessoa específica e o Fornicuti, quando todos trocam de lugar. O legal desse jogo é que vão mudando os comandos e a pessoa tem que estar muito atenta e responder rapidamente aos estímulos. É um jogo que vai melhorando o foco e a memorização.

Simone: Além de melhorar também o relacionamento. Porque a tua atenção te obriga a olhar as pessoas no rosto. Quer dizer, nós temos que olhar no olho do outro. Muitas vezes, durante o processo, você vai tropeçar nas pessoas, você vai sencostar nessas pessoas, vai te relacionar. E todos riem juntos quando todo mundo erra.

Luciana: Exato. Ele é um jogo que trabalha um aspecto muito importante que é a flexibilidade. E precisamos estar atentos ao cenário que nos cerca (...). Por que coisas podem acontecer nesse cenário (...). O que nos exige uma resposta mais imediata. Então pensando na neuroplasticidade, esse é um jogo que melhora o nosso tempo de resposta para as mudanças de cenário. Então ele pode parecer um jogo muito divertido e muito simples, mas ele traz uma série de aprendizados importantes!

Simone: Inclusive a questão da linguagem. Porque são comandos com palavras estranhas de modo que não está se utilizando um comando comum que remete diretamente a ação.

Luciana: Outros jogos que gostamos muito de usar são os chamados jogos de lista, os quais têm por objetivo trabalhar a memória e a atenção. Então, assim, podemos fazer uma lista de coisas que se levaria para uma festa, ou churrasco, ou para uma viagem. E aí as pessoas vão repetindo o que as outras levariam, tendo que repetir a lista do grupo todo. Por exemplo, eu digo, meu nome é Luciana e eu vou levar um disco na festa. Daí Revista Em Debate (UFSC), Florianópolis, volume 13, p. 162-180, 2015. ISSNe 1980-3532 
a Simone continua, dizendo o que eu levei e o que ela levaria e assim sucessivamente. Esse é um jogo que trabalha bastante a memória e nos leva a prestar mais atenção aos colegas uma vez que, na maioria das vezes, as pessoas se olham para lembrarem-se umas das outras e o que elas levariam para a festa.

Simone: Exatamente. Para não se esquecer de ninguém e/ou lembrar daquilo que o outro falou. E também temos a questão da repetição, elemento importante presente na ideia de neuroaprendizagem e que serve para ancorar novos conhecimentos.

Luciana: Isso, pois sabemos que para poder fazer um caminho neural precisamos repetir pelo menos três vezes uma informação, de preferência de formas diferentes. Então este jogo auxilia muito nisto. Eu, por exemplo, consigo decorar o nome dos meus alunos no primeiro dia de aula, o que é uma coisa muito rara, com 30, 40 pessoas em uma sala. Outro jogo que nós costumamos fazer é uma variação deste que é a Listas com Rimas. Então, quando eu quero me apresentar eu digo o meu nome com algo que rima com ele, por exemplo: meu nome é Luciana e eu sou bacana. Eu sou Simone e esse é o meu nome (...). E aí as pessoas vão repetindo e memorizado. Ancorado o som do nome, que é uma informação nova, com o som da rima, que é uma palavra mais comum, normalmente mais conhecida. Outra dinâmica que eu uso é um jogo chamado Autógrafos. Eu faço uma lista de frases de coisas do dia-a-dia, como "eu adoro acordar cedo", "eu odeio barata", "eu sou gremista", “eu sou colorado", "eu gosto do campo", "toco o instrumento musical", enfim, frases que são coisas que digam algo sobre as pessoas (...). Coisas que fogem um pouco do contexto da sala de aula e que normalmente as pessoas não compartilham. E aí eu distribuo essa lista para todos em sala de aula e as pessoas tem que marcar 10 coisas com as quais elas se identificam nessa lista. Depois ela tem que falar com seus colegas na sala de aula para descobrir quem é que tem frases em comum com ela. E isso é realmente interessante porque todos tem que falar com todos. E aí a turma se apresenta e se conhece usando uma maneira não tradicional, abandonado àquela forma comum de dizer "meu nome é tal, estou em tal semestre". E assim, as pessoas começam a descobrir coisas nos outros que elas não sabiam.

Simone: Isso. Coisas em comum. E aí se cria um link, um vínculo que faz toda a diferença na aula. Algo que eu gosto muito em sala de aula, principalmente quando Revista Em Debate (UFSC), Florianópolis, volume 13, p. 162-180, 2015. ISSNe 1980-3532 
tenho que trabalhar a questão da criatividade é o jogo Imagem e Ação. É um jogo que é simples, e não precisamos ter o jogo original em mãos para jogar. Pois podemos criar o nosso próprio jogo, utilizando os conteúdos que estamos trabalhando em aula. Pois, ele melhora a comunicação entre os alunos, de uma forma diferente dos jogos de quebragelo (...), vai mais além, trabalhando o vocabulário e a criatividade. Pois, nesse jogo é preciso se se expressar de forma criativa para passar a informação aos colegas.

Luciana: Nesse jogo Imagem e Ação, eu faço uma adaptação quando eu estou trabalhando as disciplinas de marketing, principalmente quando eu estou trabalhando posicionamento de marca. Então, eu escolho determinadas marcas e peço para que as dicas sejam características não tangíveis dessa marca. E aí eu consigo trabalhar percepção de valor sobre as marcas de uma forma diferente.

Simone: Eu utilizei na disciplina de Pensamento Visual, quando tinha vários alunos que acreditavam que não sabiam desenhar. E o importante não é saber necessariamente desenhar com precisão, e sim saber comunicar a informação por meio de imagens e figuras. E aí, mesmo um desenho de palitos resolve. Então isso foi um jogo que foi bem importante e que foi divertido jogar, pois fez com que as pessoas perdessem o medo de desenhar.

Luciana: Outro jogo que jogamos bastante é o Jogo do Avião. Seu ponto mais interessante é que, dependendo da posição que você fica no avião, vai jogar de forma diferente e apresentar sentimentos diversos. É um jogo que te coloca numa situação de desconforto, que te transforma. Por que todos ali estão sem saber direito o que está acontecendo (...). Pois você só vai descobrir o que acontece nesse jogo no final, ele faz com que você reflita sobre o seu processo de comunicação, bem como, sobre a forma como você se relaciona com os outros.

Simone: Têm também o jogo Fecha a Caixa, que trabalha com matemática, que é bem divertido, que se deve jogar rápido e estimula o pensamento quantitativo e trabalha com probabilidades.

Luciana: Sim. Esse é um jogo no qual se pode trabalhar em equipe, em grupos. Este jogo pode ser jogado tanto on-line como em um tabuleiro, que pode ser inclusive Revista Em Debate (UFSC), Florianópolis, volume 13, p. 162-180, 2015. ISSNe 1980-3532 
confeccionado pelos alunos. E, aqui, novamente estamos falando de multidisciplinaridade e interdisciplinaridade, porque trabalhamos matemática em conjunto com as habilidades manuais, por exemplo. Mas, também, é preciso mencionar os jogos colaborativos, como aquele que nós desenvolvemos e que se chama Piratamuzi. Neste jogo os peões não jogam uns contra os outros, mas sim, todos contra o tabuleiro. Assim, todos ganham ou todos perdem. E, o mais interessante desse jogo é que ele muda/inverte a lógica do ganhar e do perder. Porque, vê como é interessante: nós explicamos muito bem as regras do Piratamuzi, e deixamos muito claro que o objetivo do jogo é ganhar do tabuleiro. Mas, mesmo assim, quando as pessoas começam a jogar, elas começam jogando umas contra as outras. Elas querem se aniquilar (...). E aí quando chega no meio do jogo elas se dão conta de que ou todos vão ganhar ou todos vão perder. E aí passa a existir colaboração. E colaborar é uma competência que falta nos dias de hoje (...). Saber trabalhar junto é algo que poucos sabem fazer. Aí, temos que salientar que existe uma gama de jogos que são colaborativos e que são importantes de serem trazidos para sala de aula, independente da idade dos alunos.

Simone: Sim. Eu também acho que todos precisamos sempre ser mais colaborativos, até porque estamos vivendo um momento muito individualista de nossa sociedade.

Luciana: Eu também gosto do Dixit que é um jogo que além de ser lindo visualmente, trabalha criatividade, imaginação e vocabulário. Ele se foca nos contrários, nas similaridades, nas diferenças. E o mais legal é que ele é um jogo que nós nunca cansamos de jogar, pois as partidas são rápidas e quando termina uma rodada, logo, queremos jogar outra.

Simone: Eu apliquei o Concept, que é um jogo que ao invés de desenhar se usa das figuras do tabuleiro para passar uma informação, uma mensagem. Você não precisa desenhar, mas você deve usar uma imagem existente para descrever uma ideia.

Luciana: Acho importante destacar esses dois jogos porque eles focam no pensamento visual. E, também, porque, para que possamos traduzir uma ideia em uma imagem, é preciso que tenhamos essa ideia muito clara. Pois, se não você não domina um conceito, você não conseguirá transformar esse em uma imagem. Então, quando trazemos para a sala de aula conceitos que possamos trabalhar de forma visual, desenhando, estamos Revista Em Debate (UFSC), Florianópolis, volume 13, p. 162-180, 2015. ISSNe 1980-3532 
estimulando que o aluno faça um processamento mais profundo. E, claro é um processo que é divertido, mesmo que ele só saiba desenhar de palitinho e vá rir do seu desenho. Ele vai lembrar-se da sua infância, tem uma ancoragem emocional, mas ao mesmo ele está fazendo um processamento de informação muito profundo. E, esse processo de ilustração é muito válido para o aprendizado e para a fixação de conteúdos na memória de modo que, são comuns, os relatos de alunos que ao chegar no dia da prova dizem que se lembraram do desenho que eu coloquei no mapa mental e, daí lembrou-se do resto e respondeu a questão. E, justamente para isso que servem os mapas mentais (...).

Simone: O que é mais um input nessa informação. Ou seja, a informação ouvida, a informação escrita e a informação visualizada. Aí temos os três inputs da informação, as três vias de repetição de uma forma não é igual. Porque repetir igual não tem muito sentido.

Luciana: Então acho que é bem por aí (...). Que sempre que pudermos devemos propor algo que se possa desenhar, ou que se possa representar (...). Propor atividades que vão além do escrever. Pois isso força o aluno a processar a informação/conhecimento de um modo diferente e, por consequência, implica na formação de um caminho neural mais forte.

Mauro: Bem, meninas, acho que vamos ficando por aqui. Mas, permito-me antes de encerrar, puxar a brasa para a sardinha das Ciências Sociais e fazer apenas duas breves colocações.

\section{Simone e Luciana: Quais?}

Mauro: A primeira é que, eu fiz algumas pontes e acabei me lembrando dos meus alunos de estágio-docente de quando fiz a licenciatura e no quão esse tipo de abordagem foi importante e marcante para eles quando, anos depois, encontrei com alguns deles e eles me disseram que sempre que comiam uma laranja se lembravam das aulas de Sociologia. Pois, havia usado desta bendita fruta para explicar a relação intrínseca entre infra e superestrutura para Marx de modo bastante simples, apenas cortando a laranja no meio e escrevendo na parte inferior infraestrutura e na superior superestrutura e, a partir disso, ao deslocar a parte superior (superestrutura ideológica) mostrar que a parte Revista Em Debate (UFSC), Florianópolis, volume 13, p. 162-180, 2015. ISSNe 1980-3532 
inferior permanecia (infraestrutura material) e, depois, virando de cabeça para baixo a laranja, realizar a mesma ação, deslocando a parte superior (agora, representando a infraestrutura material) e mostrar que a parte inferior permanecia (esta, agora, representando a superestrutura ideológica) de modo que, por dedução lógica, se chegava à conclusão que a infraestrutura material e superestrutura ideológica estão intrinsecamente relacionadas e se condicionam mutuamente, algo muito bem expresso numa conhecida frase de Marx que diz que, um problema só surge no seio de uma sociedade quando, esta, já possuí os instrumentos que lhe permitiram solvê-lo.

\section{Luciana: E a segunda?}

Mauro: A segunda é que, esse é um desafio e tanto. Que sempre haverão resistências. Não somente por parte dos alunos, como vocês já falaram. Mas, também e principalmente por parte dos nossos colegas professores na medida em que, usar esse tipo de abordagem implica em pensar a educação desde outra perspectiva. Uma perspectiva que para os alunos é contagiante e envolvente - mas que para os professores mais antigos e já há muito na profissão significa sair de sua zona de conforto. E, é, aí, a meu ver, que está o maior desafio a ser enfrentado pelas Ciências Sociais, qual seja, de se romper com passado e de se pensar em uma "sociologia que não sirva somente ao tempo presente, mas que, também, esteja voltada para o futuro".

\section{Referências}

HUIZINGA, J. Homo Ludens. São Paulo: Perspectiva, 2008.

SCHELL, J. The Art of Game Design: A book of lenses. CRC Press, 2014.

DELORS, J. Educação: um Tesouro a Descobrir; Cortez Editora, 2014.

STREAN, W. B. Creating Student Engagement? HMM: Teaching and Learning with Humor, Music, and Movement. Creative Education, 02 (03), 2011, pp.189-192. 